\title{
Experiencias
}

\section{Atención educativa online a alumnas con discapacidad visual de 3 a 5 años: «Nuestra casa no es mi cole»}

\author{
Online education for 3- to 5-year-old girls with visual disability: \\ 'Our house isn't my school'
}

\section{Vecilla Rodrigo}

\section{Resumen}

Se muestra una experiencia de abordaje de intervención educativa online con alumnas de educación infantil de segundo ciclo con grave discapacidad visual, en la que se han destacado cuatro necesidades. En primer lugar, construir un nuevo espacio significativo para el encuentro y el trabajo educativo efectivo que sustituya a los valores emocionales de referente de seguridad, regulación emocional y estímulo al aprendizaje que suponen las aulas de infantil, en las que no podíamos encontrarnos. En segundo lugar, generar un nuevo tempo en las intervenciones online que no solo dé cabida, sino que priorice el trabajo con las emociones presentes y desde estas, como único modo de conseguir que la atención online en educación infantil resulte efectiva. En tercer lugar, crear materiales que cumplan los principios del diseño universal para el aprendizaje (DUA), proporcionando múltiples formas de representación, múltiples opciones para el lenguaje y los símbolos y múltiples opciones para la comprensión. Y, por último, compaginar equilibradamente, la atención a alumnas y familias, de modo que suponga una vivencia compartida -familia, profesionales, alumnas-, de resiliencia ante lo inédito, que nos coloca a todos en situación de vulnerabilidad, de la que partir y sobre la que persistir y aprender.

\section{Palabras clave}

Educación infantil. Educación online. Currículo emocional. Diseño Universal del Aprendizaje. Resiliencia en red. 


\begin{abstract}
The online educational experience described, designed for 3- to 6-year-old pre-school girls with severe visual disability, entailed attending to four needs. Firstly, a significant new space had to be established for contact and effective education. That space would have to be able to stand in for the emotional values present in primary school in-person classrooms, subject to lockdown, around safety, emotional control and learning stimulus. Secondly, a new tempo had to be generated for online activities that not only accommodated but prioritised working with and using emotions as the sole vehicle apt to ensure the efficacy of online pre-school education. Thirdly, Universal Design for Learning (UDL)-compliant materials had to be created and alternative approaches to representation, language, use of symbols and cognition had to be proposed. Lastly, a balance had to be sought in the support afforded students and families sharing professionals' persistent and resilient handling of unprecedented, vulnerability-inducing situations in the pursuit of effective learning.
\end{abstract}

\title{
Key words
}

Pre-school education. Online education. Emotional curriculum. Universal Design for Learning. Network resilience.

\section{Aprendizaje a lo largo de toda la vida}

Parecía que lo teníamos plenamente integrado, incluso recogido está en nuestra legislación educativa actual. Y seguimos en él, en tiempo de aprendizaje. Pero, quizá, los adultos lo habíamos olvidado de alguna manera, y habíamos llegado a considerar que lo teníamos todo bastante controlado.

Y llegó la pandemia, y con ella, el teletrabajo, la educación online, la intensificación de la convivencia familiar, el aislamiento respecto a redes sociales más amplias y muchas cosas más, que se impusieron en nuestras vidas.

Y cualquiera diría ahora que los únicos que tenían integrado de modo vivencial este principio del «Aprendizaje a lo largo de toda la vida» eran los niños y las niñas, a pesar de no estar informados acerca de dicho planteamiento socioeducativo...

Hace un año, en marzo de 2020, nos encontrábamos indagando y buscando recursos y fórmulas para conseguir que las sesiones de atención educativa

Vecilla, I. (2021). Atención educativa online a alumnas con discapacidad visual de 3 a 5 años: «Nuestra casa no es mi cole». RED Visual: Revista Especializada en Discapacidad Visual, 77, 200-227. https:/doi.org/10.53094/ JXGW7586. 
online -que imponía el confinamiento provocado por la pandemia de covid- con cuatro alumnas de educación infantil con discapacidad visual resultasen posibles y eficaces.

Partíamos de cierta experiencia previa de atención y apoyo en domicilio en estas etapas educativas, cuando circunstancias puntuales así lo requerían. Pero esta situación fue completamente nueva e inesperada para todos. Será atención en domicilio, sí, pero online. Nadie, ni las familias, ni los niños, ni los profesionales, tenían experiencia previa ni formación al respecto.

Cierto es que, en este proceso de aprendizaje a lo largo de toda la vida, hay algo muy estimulante, y es que, en el momento más insospechado, podremos revivir la sensación de «La primera vez que...».

Buscar fórmulas, recursos, estrategias y soportes para lograr que esas sesiones de apoyo educativo online en la etapa de infantil, que se imponían, fuesen gratificantes y efectivas era lo que había que conseguir ahora. Llegarían muchas ocasiones de este tipo: «Es la primera vez que utilizamos esta plataforma, no sabemos si...».

Entre estas cuatro alumnas de educación infantil de segundo ciclo, la más pequeña, de 3 años y con discapacidad visual por glaucoma, estaba recién escolarizada ese mismo curso 2019-2020 en el colegio de su pueblo, y durante esos dos trimestres en el aula, los aprendizajes habían sido intensos para todos los implicados.

Aquel primer día de septiembre de 2019, la entrada en el aula había generado mucho vértigo en la familia $y$, por tanto, en la niña también, así como entre los profesionales del colegio, que carecían de experiencia en la inclusión de alumnas con discapacidad visual.

Pero todo había ido evolucionando muy bien. Había un buen desenvolvimiento de las relaciones con iguales, del juego en los recreos, del respeto a las rutinas de aula, de la participación en las actividades grupales e individuales... Y se había logrado una buena coordinación interprofesional, que había generado confianza en la familia y en la niña, que acudía feliz a su aula cada día.

Y, de pronto, el 13 de marzo de 2020, cinco meses después de iniciar la aventura de la escolarización, volvíamos a casa.

Vecilla, I. (2021). Atención educativa online a alumnas con discapacidad visual de 3 a 5 años: «Nuestra casa no es mi cole». RED Visual: Revista Especializada en Discapacidad Visual, 77, 200-227. https://doi.org/10.53094/ JXGW7586. 
En nuestra primera clase virtual, que pudimos hacer por WhatsApp con los teléfonos móviles en marzo de 2020, la alumna dijo de modo muy asertivo y tranquilo: «Nuestra casa no es mi cole». Era obvio que decía la verdad.

Y es que nada funcionaba para un buen discurrir de la sesión: había una gran dispersión en ella, en la alumna (que, en adelante, llamaremos Henar), además de un explícito rechazo a hacer cualquier cosa que le resonase a tarea escolar.

En su casa hay espacios para jugar, dormir, ver la televisión, cocinar y comer juntos... No hay pupitres, ni pizarras, ni carteles, ni cuadernos de fichas, ni rincones, ni alfombra para asamblea, ni mascota, ni letras, ni números, ni figuras... No hay otros niños y niñas, ni maestras. $Y$ no hay horarios ni rutinas que inviten a concentrarse para aprender cosas nuevas.

En definitiva, no se dispone de un entorno ni físico ni social que invoque intereses y atención, motivaciones y refuerzos, dirigidos al currículo de educación infantil. Es más, se está rodeado de estímulos dirigidos a otros intereses: familiares, de juego, de descanso, de afecto, de vida cotidiana... Estamos en un contexto físico y social también seguro y estimulante, como lo es cualquier aula de educación infantil, pero diseñado para hacer otras cosas.

Los estudiantes de ciclos superiores de primaria, ESO o bachillerato pueden ya crear su propio espacio/tiempo de estudio, porque su intención les va permitiendo tomar decisiones y acciones que les hacen más independientes del entorno, autónomos en este sentido. Pero los pequeños de educación infantil aún no están en condiciones de hacer esto. De modo que corresponde a los demás intervenir aquí.

Y este es el primer gran reto de la educación infantil online, que marca una gran diferencia respecto a otras etapas educativas.

Henar parecía sentirse plenamente satisfecha al transmitir este hecho irrefutable, «Nuestra casa no es mi cole», que bien puede recibirse como una declaración de intenciones. Incluso como un aviso a navegantes. De algún modo, nos hacía conscientes de la dimensión del reto que teníamos por delante.

Y, efectivamente, cualquier intento de desarrollar actividades relacionadas con aprendizajes escolares era inmediatamente obviado por Henar... Ya fuese enumerar 
o colocar o adivinar o clasificar formas... Solo quería jugar, porque ella estaba en su casa con su familia, no en el colegio.

A la situación descrita de la alumna, de vuelta a su contexto familiar, inmersa en un entorno, tanto físico como social, bien diferente de su aula y al cual ya nos ha expresado su total apego, y a cuyos requerimientos, bien diferentes de los del colegio, está dispuesta a entregarse, hay que añadir el incipiente desconcierto en su madre:

Ella no quiere hacer nada de lo que nos envía su tutora del colegio. Y yo no quiero forzarla. No hay manera: juega con sus hermanas o con su padre todo el día. $\mathrm{Ni}$ siquiera quiere entrar online con la maestra y con las amigas del aula. Si está feliz y juega, yo no pido más, bastante tenemos con no poder salir de casa, ni ver a las abuelas...

Tras esta primera sesión online nada alentadora, el paso siguiente era contactar, también online, con la tutora del aula y pedirle una guía del trabajo que se estaba haciendo desde el colegio con el grupo-clase, así como consensuar cuáles serían los objetivos clave para esta alumna en esta situación.

En realidad, ya los conocíamos, pues llevábamos dos trimestres trabajando juntas en el aula. Y, en todo caso, se trataba de reforzar los objetivos y contenidos de los dos trimestres anteriores, no de seguir avanzando en el currículo, abordando nuevos aprendizajes.

El siguiente aprendizaje que se imponía, era buscar «el medio»..., con problemas de conexión de domicilio a domicilio, sin conocimientos sobre plataformas de videollamadas ni experiencia previa, ni por nuestra parte ni por parte de la familia.

Por momentos, las cosas se complicaban para todos. Pero, compartir la_búsqueda con las familias, e insistir en pruebas diversas, iba permitiéndonos resistir de modo conjunto y esperanzado. Era un aprendizaje acelerado, pero aprendizaje al fin.

Y así, cada día, tras la sesión, quedábamos para la semana próxima, y, para nuestra sorpresa - pues nos despedíamos con la sensación de haber fracasado rotundamente-, allí estaba Henar, esperando a ver qué le ofrecíamos en cada encuentro online. 


\section{La creación de un espacio virtual para el encuentro}

Se presentaban dos grandes motivos para seguir indagando:

1. La alumna parecía tener expectativas positivas respecto a nuestras sesiones online, pues nunca faltaba, y hacía preguntas, sugerencias... Además, parecía que le sentaban bien. Cada sesión acababa hablando de qué vamos a hacer el próximo día.

2. Puesto que nada se estaba haciendo en casa que pudiera suponer una continuación del trabajo escolar, sentíamos la obligación de poner algo de rutina, de organización, de sosiego, de camino..., en esta inesperada vuelta a cierto caos que puede suponer un hacer constante sin horario ni objetivos.

Decimos esto, aun considerando que el juego libre es un potente medio de aprendizajes y adquisición de competencias en la primera infancia, sin duda, pero al juego libre se le pueden «añadir» estructuras que refuercen o inciten la práctica de esas otras competencias básicas que hay que trabajar en infantil para favorecer el desarrollo de todo el potencial de cada niño.

Había que persistir en el reto, dado que estas dos motivaciones resultaban ineludibles. Por un lado, la confianza y las expectativas de la pequeña, a pesar de nuestra sensación de fracaso como enseñantes, eran un potente acicate, que, si bien nos dejaba perplejos, a la vez impulsaba a responder.

La motivación y las expectativas positivas son un gran valor en procesos de aprendizaje, y un profesional de la educación no puede desoír esta energía.

En alguna ocasión, se podía pensar que lo que estaba resultando interesante para Henar era percibir a su maestra de apoyo en un lugar vulnerable: quien era su profesora, quien, hasta hoy, le habría parecido alguien con pleno control de todas las situaciones, capaz de apoyarla en sus dificultades en el aula o en el recreo, de pronto, aquí estaba ese adulto referente para ella, tan vulnerable y perdida ante lo inédito como ella misma. Sin duda, tenía que parecerle interesante, incluso divertido. Sea como fuere, la cuestión era despertar interés. Y sostenerlo.

Y, por otro lado, resonaba la certeza de que, como maestra de apoyo a alumnas con discapacidad visual, correspondía resolver las dificultades que entrañaba esta nueva

Vecilla, I. (2021). Atención educativa online a alumnas con discapacidad visual de 3 a 5 años: «Nuestra casa no es mi cole». RED Visual: Revista Especializada en Discapacidad Visual, 77, 200-227. https:/doi.org/10.53094/ JXGW7586. 
modalidad de atención educativa, que no podía pararse, dando al traste con todo lo trabajado y conseguido hasta ahora.

Ya sabemos lo que son tres meses sin colegio para el alumnado de educación infantil...

Un reto con muchísimas dimensiones:

- Nuevo espacio de encuentro sin referentes físicos ni rutinas, como hay en cualquier aula, y que están diseñados para centrar la atención e intención hacia determinados comportamientos, tareas e intereses... Ella estaba en su casa, que es otra cosa, y lo había dejado muy claro. Era preciso crear un espacio de encuentro común que le resultase motivante y con capacidad para acoger y promover aprendizajes y las competencias correspondientes.

- Inédita plataforma de encuentro online. Las madres, los padres, los hermanos mayores y los profesionales de apoyo educativo compartimos muchos ratos de indagación y pruebas, hasta que conseguimos dar con alguna precaria opción que nos permitía «compartir pantalla» y sin límite de tiempo.

- Nueva gestión del tiempo. Esto resultó ser muy importante, dado que atraer y centrar la atención de los más pequeños requería mucho tiempo. Y resultaba catastrófico que, de repente, hubiera que despedirse porque habían pasado los 40 minutos a los que nos limitaban algunas plataformas. Esto generaba en Henar más desconcierto, más enfado, más desconfianza... Y no nos lo podíamos permitir.

Sabemos que en el cerebro humano los aprendizajes no pueden funcionar así. Nos lo dice la neurodidáctica. Y mucho menos con una niña de 3 o 4 o 5 años. De hecho, nuestras sesiones online solían durar una hora y media o más.

- Compartir pantalla, sí, pero ¿para qué? Si la pequeña no quería ni oír hablar de fichas, entonces, ¿qué contenidos, qué propuestas podíamos ofrecerle en esa pantalla compartida, ahora que sabíamos manejarla? Tenía que ser un material ajustado a la vez a la adquisición de competencias básicas del currículo de infantil, y/o del «currículo» específico para alumnas con discapacidad visual, y también ajustado a esta situación emocional de desarraigo escolar, que comportaba labilidad atencional, desapego por contenidos escolares... 
- La madre había pasado a ser una compañera en las sesiones de intervención. Su presencia era, en muchos momentos, imprescindible. En otros momentos, resultaba que podía distorsionar la conducta o la expresión o la concentración de la niña. Y en otros momentos, podía compartir, reforzar y disfrutar lo que estábamos haciendo. Y aún había otros momentos en los que la interacción y el diálogo se dirigían en exclusiva a ella, a la madre, a abordar sus preguntas respecto a lo que estaba pasando en la vida cotidiana de sus hijas.

Esta circunstancia asemejaba a lo que son las intervenciones en domicilio, pero tampoco era lo mismo, ni para la madre ni para nosotros. Ni para Henar, que a veces se enfadaba al sentir que le quitábamos su espacio-tiempo con nuestras «cosas de mayores». Y, sencillamente, se iba sin despedirse.

\section{La escucha de lo vivencial como punto de partida para la intervención educativa}

Ya encontrada una plataforma online adecuada y definidas las competencias básicas sobre las que trabajar, se decidió que la actividad principal y más rentable iba a ser la más simple: escuchar a la pequeña.

Y fue un acierto, ya que en esta posición de escucha sin expectativas ni objetivos a priori, fue posible captar su gran interés por conocer qué hacíamos las demás personas en nuestras casas todo el día, con quiénes estábamos...

Esa curiosidad por lo cotidiano y lo vivencial de otras personas tenía un potencial que no se podía obviar. Había que encontrar el modo de aproximar sus intereses actuales a nuestros objetivos, y trabajar desde ahí, desde donde estaba la alumna.

Apareció una opción interesante: presentarle a Dúo, un perro que vive en el domicilio desde el que se hacen las sesiones online, que a las cuatro alumnas les encantó. A los niños, los animales les despiertan mucha empatía.

Se podían generar muchas maneras de, digamos, «utilizarle», para traer a las sesiones diversidad de contenidos del currículo de infantil a trabajar. Pero no estábamos de suerte, como creíamos inicialmente, porque el perro, siendo una criatura preciosa, por 
lo demás, no deja de ser un perro, así que rechazaba de plano esa rarísima situación de escuchar conversaciones dirigidas a una pantalla de la que salían voces, incluso voces conocidas y apreciadas por él, pero que ni olían a nada ni se podían tocar. De modo que, en cuanto se entraba a través del ordenador para iniciar una sesión, él huía al otro lado de la casa. Nada funcionaba para traerle ante la pantalla.

Así, de la narración sobre aventuras del perro, podían surgir diversidad de propuestas acordes a los contenidos de infantil, como, por ejemplo:

- Clasificación de objetos cotidianos según su textura suave o rugosa, o por su olor agradable o desagradable, para dar pistas a Dúo.

- Enumeración de rutinas saludables para convencer al perro y que las adoptase.

- Búsqueda de palabras que empiecen por la sílaba «du», ya que el perro ha decidido cambiarse de nombre, pero quiere que siga empezando por «Du-». Se piden ideas en la sesión, hasta encontrar algo que nos guste a todas. Se puede proporcionar ejemplos a las alumnas, si es preciso.

A este tipo de propuestas se añadieron cinco marionetas con sus voces y sus historias: oso Usi, ratón Tom, cabra Bra, gallina Llina y un pájaro azul Ilamado Hugo (ver Figura 1). Se presentaron como criaturas que también se habían quedado sin colegio, que tampoco podían ir a jugar con sus amigos ni a visitar a sus abuelos, y que pasaban el día en nuestra casa.

Figura 1. Captura de pantalla de una sesión online

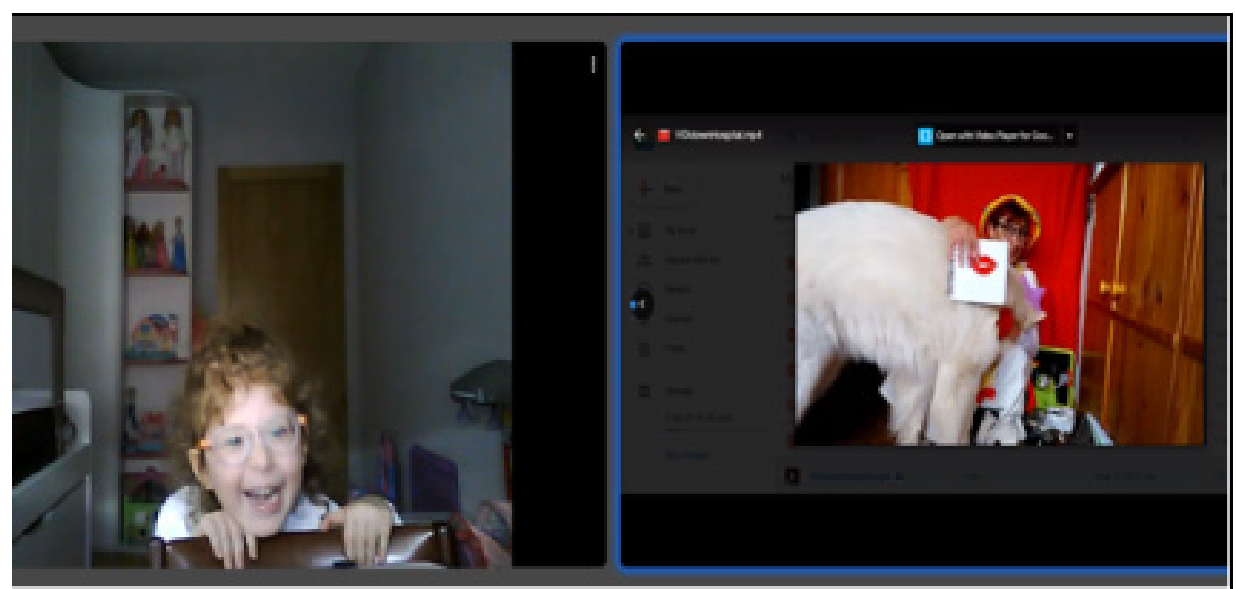

Vecilla, I. (2021). Atención educativa online a alumnas con discapacidad visual de 3 a 5 años: «Nuestra casa no es mi cole». RED Visual: Revista Especializada en Discapacidad Visual, 77, 200-227. https://doi.org/10.53094/ JXGW7586. 
Fue naciendo con ellas ese nuevo «espacio-tiempo» común, de interés para las alumnas, a modo de nueva red social virtual cuya compañía les interesaba, y con quienes gustaban de encontrarse cada semana.

Y en este nuevo contexto, nació uno de los primeros materiales que se utilizaron en las sesiones: la adaptación del cuento Nadarín, de Leo Lionni, publicado en 1963 por la editorial Lumen y traducido por Ana M.a Matute (Lionni, 1963).

En una de las sesiones con Henar, la pequeña de 3 años, tras hacer un gran despliegue de marionetas, ella preguntó: «¿Y en tu casa no tienes peces? Yo lo que quiero es ver un pez».

Encontramos este cuento, ya un clásico de la literatura infantil, reeditado varias veces, y comenzamos su narración oral en la sesión a través de la pantalla, describiendo y mostrando algunas de sus ilustraciones. La pequeña participaba de la narración, incluyendo sus propias expresiones.

De esta improvisación surgió la adaptación del cuento en un PowerPoint (Figura 2), procurando el máximo contraste en breves textos que recogían las expresiones de la propia niña la primera vez que le narramos el cuento.

Figura 2. Captura de pantalla de una sesión con Nadarín

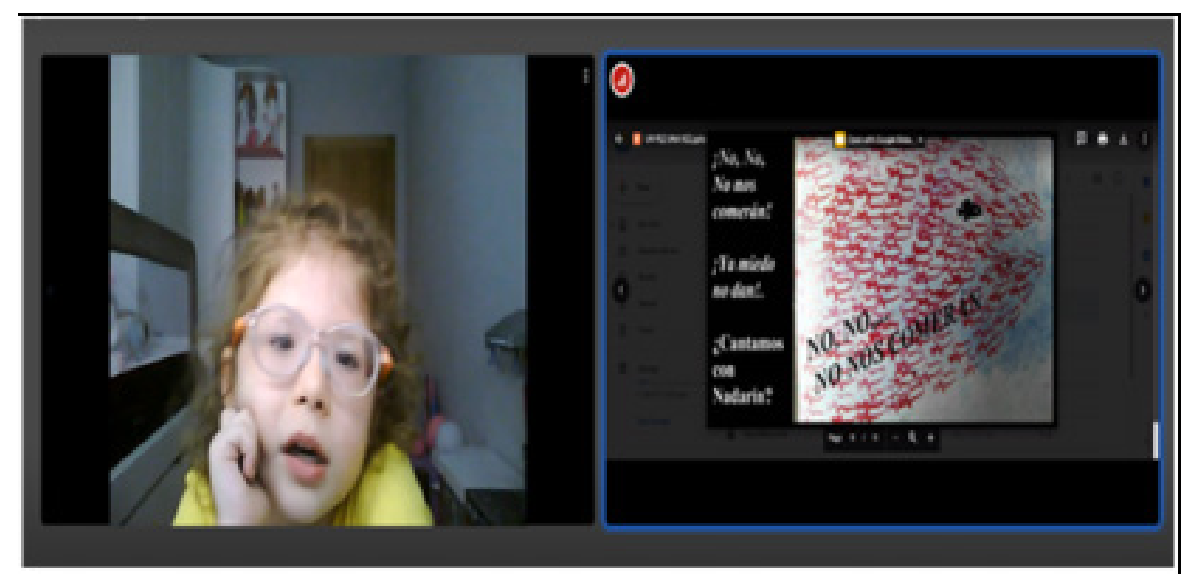

Además, se seleccionaron y adaptaron las imágenes originales que, para una alumna con discapacidad visual, resultaban poco significativas por tener colores muy suaves, con poco contraste y demasiadas figuras, de tal modo que solamente incluían cierta 
«dificultad superable», para, así, trabajar habilidades perceptivo-visuales de búsqueda organizada, discriminación figura-fondo, complementación perceptual, conceptos espaciales... Todo esto, sin que ella lo sospechara siquiera.

Y como al pez le pasan muchas cosas, había que recordar en qué orden le habían ido sucediendo, y así se conseguía trabajar también la secuenciación temporal.

Y la resolución de problemas, porque Nadarín tenía algunos problemas que resolver: tenía miedo porque era muy pequeño. «iQué casualidad!», la pequeña Henar también tenía miedo, pero decía que no sabía a qué tenía miedo. Quizá por esta razón la adaptación del cuento, que apareció en respuesta a su demanda y que incluía sus propias expresiones, llegó a gustarle tanto. Y también a las otras tres alumnas de infantil, que además de trabajar estas mismas competencias, ya podían leer alguna palabra, o buscar alguna sílaba determinada...

En el PowerPoint, también se incorporó la grabación del cuento, de modo que las cuatro niñas podían escucharlo, o simular que lo leían ellas mismas, a partir de las imágenes, de su memoria y de sus incipientes habilidades lectoras. O pedir que se lo leyeran o que se lo contarán sus padres. Había múltiples opciones.

\section{Diseño universal del aprendizaje}

En definitiva, la adaptación de Nadarín resultaba tener muchas posibilidades para percibir, utilizar y comprender el contenido, tal y como proponen los principios y pautas del diseño universal para el aprendizaje (DUA), que se define como un enfoque basado en un diseño curricular que permite a todas las personas desarrollar conocimientos, habilidades y motivación e implicación, con su proceso de aprendizaje.

Este planteamiento de los procesos de enseñanza-aprendizaje implica la creación de diseños flexibles y significativos que presenten opciones personalizables que permitan a cada cual progresar desde donde está, desde su zona de desarrollo real (ZDR), y no desde donde nosotros imaginamos que está.

Y, por lo mismo, favorece una práctica que permite al alumno dirigirse a su verdadera zona de desarrollo próximo (ZDP), y no al objetivo curricular que se haya decidido para él. 
Es decir, el foco de la dificultad de aprendizaje se desplaza ahora del alumno a los materiales y medios y al diseño curricular en general, de manera que un currículo constituirá una barrera al aprendizaje en la medida en que no permita que cada alumno pueda acceder a él (Alba et al., 2014).

Y las barreras pueden ser muchas: desde un diseño rígido o inaccesible de los recursos, hasta el hecho de obviar el estado emocional en la intervención, en lugar de partir de él.

Los fundadores del DUA, David H. Rose (neuropsicólogo del desarrollo) y Anne Meyer (experta en educación, psicología clínica y diseño gráfico), indican que no habrá opción a aprendizaje significativo si obviamos la diversidad cerebral: no hay dos personas que aprendan del mismo modo.

Pero, además, no habrá aprendizaje para nadie si no tenemos en consideración la relación entre los tres tipos de subredes cerebrales que intervienen de modo preponderante en el proceso de aprendizaje y que están especializadas en tareas específicas del procesamiento de la información o ejecución (Rose y Meyer, 2002):

1. Redes de reconocimiento: especializadas en percibir la información y asignarle significados. En la práctica, estas redes permiten reconocer letras, números, símbolos, palabras, objetos..., además de otros patrones más complejos, como el estilo literario de un escritor, y conceptos abstractos, como la libertad.

2. Redes estratégicas: especializadas en planificar, ejecutar y monitorizar las tareas motrices y mentales. En la práctica, estas redes permiten a las personas desde sacar un libro de una mochila hasta diseñar la estructura y la escritura de un comentario de texto.

3. Redes afectivas: especializadas en asignar significados emocionales a las tareas. Están relacionadas con la motivación y la implicación en el propio aprendizaje. En la práctica, estas redes están influidas por los intereses de las personas, el estado de ánimo o las experiencias previas. 


\section{Recursos digitales}

Parecía que se empezaba a tener éxito, pues aquel pez que Henar había demandado, nadaba por su ZDR y la llevaba a su ritmo, al ritmo de sus intereses, a su ZDP, favoreciendo la práctica de competencias básicas curriculares (escuchar y aprender narraciones orales, secuenciar y relacionar hechos, reconocer fonemas y grafías, contar, describir, ubicar, practicar habilidades perceptivovisuales...) mientras disfrutaba.

Este hecho reforzaba la confianza en los principios del aprendizaje significativo y de la educación inclusiva, plenamente concordantes con los planteamientos de un DUA (Booth et al., 2006):

- Hay que repensar el currículo en todos sus componentes: objetivos, recursos, tareas..., y ajustarlos a las capacidades e intereses de cada aprendiz.

- Hay que planificar la intervención para lograr que el alumno sienta que es bienvenido y valioso, y que siempre va a lograr el éxito en cada paso de los procesos de aprendizaje, lo cual solamente será posible si se siente partícipe activo de los mismos, capacitado para tomar decisiones al respecto y, cómo no, en conexión con sus experiencias previas y actuales.

Todo esto se veía ahora facilitado por la utilización de recursos elaborados de modo personalizado, al tratarse de una atención individual, y también por el hecho de tener que recurrir necesariamente a diseños digitales, que permiten numerosos ajustes y modalidades diversas de presentación de los materiales sobre los cuales trabajar.

Nos parecía que, al abordar las dificultades de la intervención educativa online en educación infantil, no todo lo que encontrábamos eran limitaciones y dificultades, también empezaban a aparecer algunas aportaciones muy valiosas para promover aprendizajes significativos en nuestras alumnas.

El caso de Nadarín tuvo también buena acogida por parte de otras tres alumnas de segundo ciclo de infantil: una alumna de segundo curso, con la que podía compartir la lectura de algunas palabras, identificar fonemas y grafemas, jugar con las rimas, inventar otras aventuras para Nadarín y escribir sus títulos... Y otras dos alumnas de tercer curso de infantil, que han iniciado primaria en el curso actual, con las que se

Vecilla, I. (2021). Atención educativa online a alumnas con discapacidad visual de 3 a 5 años: «Nuestra casa no es mi cole». RED Visual: Revista Especializada en Discapacidad Visual, 77, 200-227. https://doi.org/10.53094/ JXGW7586. 
podía hacer una lectura compartida de frases, jugar con cambios de entonación o de ritmo de lectura, establecer turnos, etc.

Y dado que algunas de estas alumnas, ya lectoras principiantes, descubrieron que, a veces, era más divertido, más motivante y mucho más accesible leer en la pantalla del ordenador, con letras más grandes, con tipos de letras nuevas, modificando los contrastes, seleccionando y mejorando las características de las ilustraciones..., tanto nosotros como sus madres intercambiábamos ideas y recursos para adaptar textos para ellas:

- Textos de los que les enviaban de cada aula.

- Textos de cuentos que les habían contado cuando aún no leían y les habían encantado, pero cuya edición actual, de gran atractivo visual, era compleja para ellas por diversas características: tipo de letra, tamaño, contrastes, ubicación de textos e imágenes...

Nuevamente aquí, la colaboración con las familias, su presencia en las sesiones, derivaba en una reflexión sobre los progresos y las dificultades concretas de cada alumna, y generaba un trabajo compartido de mejora y adaptación de materiales, ya fuesen escolares o de ocio.

Y también, empezaba a resultar de interés explorar a escribir con el teclado del ordenador.

Cuando estamos en el tercer trimestre del tercer curso de educación infantil, como sucede con dos de estas alumnas, la presión sobre el aprendizaje de la lectoescritura puede resultar abrumadora para niñas y familias, y puede generar tensiones que en nada ayudan al proceso de consolidación de las competencias lectoras de las pequeñas con discapacidad visual.

Y con todas ellas se pudo abordar el tema de los miedos, de cómo los expresamos, de cómo los superamos... Porque a estas edades, y más en esta situación de pandemia y confinamiento, con tantos y tan rápidos cambios, los miedos de los más pequeños «corren que vuelan» (tal como nos compartía la madre de una de estas alumnas), y nos corresponde escucharlos e intervenir sobre ellos.

Sobre esto, sobre la educación emocional en la etapa de infantil y la intervención de apoyo a alumnas y familias en tiempos de incertidumbre, hablaremos más adelante.

Vecilla, I. (2021). Atención educativa online a alumnas con discapacidad visual de 3 a 5 años: «Nuestra casa no es mi cole». RED Visual: Revista Especializada en Discapacidad Visual, 77, 200-227. https://doi.org/10.53094/ JXGW7586. 


\section{Nueva red social}

En ocasiones, lo que parece un infortunio, acaba siendo un estímulo para la creación de soluciones que aportan nuevas oportunidades. Y así fue el día que, al iniciar una sesión con Henar, nuestra alumna de 3 años, ella preguntó por nuestros amigos, las cuatro marionetas que nos acompañaban en cada sesión, pero no sabíamos en ese momento dónde las habíamos guardado. Habíamos descuidado lo que constituía nuestro espacio-tiempo de encuentro, ese lugar virtual seguro y estimulante en el que se desarrollaban nuestras sesiones.

Fue como perder a la mascota de cada aula, y eso es algo que no puede suceder nunca. Para que este hecho no diese lugar a un desencanto que nos pondría en situación de pérdida de la confianza y del interés conseguidos hasta el momento, inventamos un evento que explicaba la ausencia de las marionetas: les gustaba jugar a esconderse y hoy no había modo de encontrarlas. Y ya no quedaba más remedio que construir un nuevo material a partir de esta historia, este evento, que le había resultado muy importante (Figura 3 ).

Figura 3. Sesión online con las cuatro marionetas

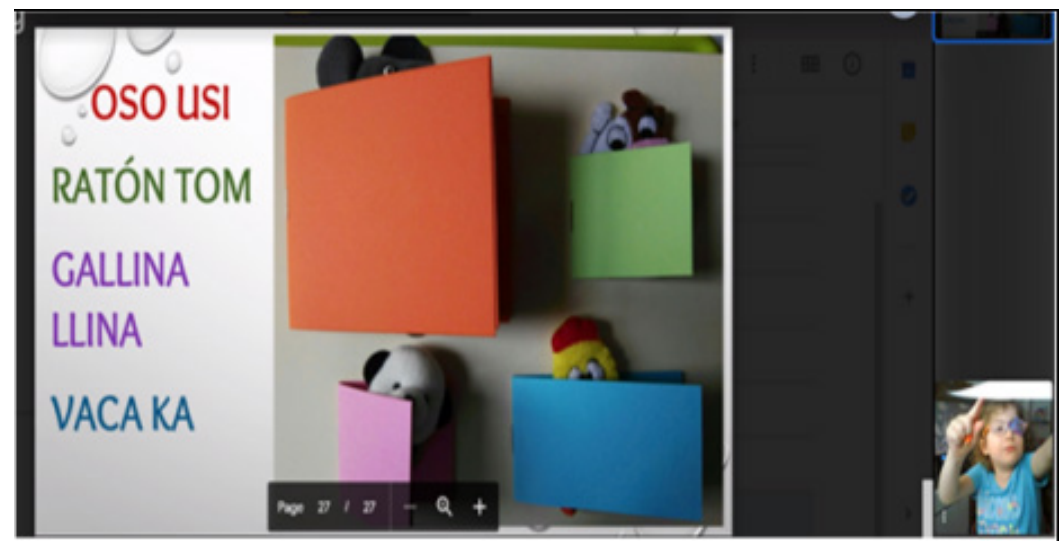

Así nació esta vez, inspirado también en la escucha y la respuesta a los intereses de las pequeñas alumnas, el nuevo material, Ayúdame a buscar, un nuevo PowerPoint con el que pudimos trabajar varias sesiones. PowerPoint de 27 diapositivas y que se ajusta a los principios del DUA, de la educación inclusiva y del aprendizaje significativo que hemos mencionado anteriormente, y que incluye:

- 27 fotografías realizadas en el entorno, con objetos y espacios reales.

Vecilla, I. (2021). Atención educativa online a alumnas con discapacidad visual de 3 a 5 años: «Nuestra casa no es mi cole». RED Visual: Revista Especializada en Discapacidad Visual, 77, 200-227. https://doi.org/10.53094/ JXGW7586. 
- Texto de creación propia, generado a partir de diálogos con las alumnas sobre eventos de su interés. Este texto aparece escrito en 17 diapositivas, acompañando a las fotografías, con variedad de contrastes y tipos de letra. El diseño está pensado para alumnas de infantil de segundo ciclo, tanto de 3 como de 4 y 5 años.

- Audio con la narración de la historia, con una duración de 2:40 min.

\subsection{La propuesta}

Se invitó a nuestras alumnas a que ayudasen a buscar a nuestros nuevos amigos: oso Usi y ratón Tom. Les recordamos que uno de sus juegos preferidos es esconderse y les pedimos que nos acompañen para encontrarlos.

Sabemos que para las alumnas del ciclo de infantil hay dos aspectos motivantes en este planteamiento de la tarea:

a. Ayudar a un adulto significa recibir confianza y adquirir sentimiento de competencia.

b. Jugar a acompañar a personajes que ya conocen y con los que han interactuado en clases virtuales previas es otra potente motivación para centrar la atención y poner en juego todas nuestras habilidades.

Ya se ha comentado que las marionetas estaban presentes y participaban de todas las sesiones. Es más, la intención inicial y principal para las alumnas en cada sesión era saber algo de oso Usi, ratón Tom, gallina Llina, cabra Bra... Empezaban preguntando por ellos y acababan con un «Hasta la próxima amigos».

\subsection{Los objetivos}

1. Trabajar habilidades perceptivas: figura/fondo, completación, posición y relaciones espaciales...

2. Trabajar secuenciación temporal a través del cuento narrado: «¿Qué sucede primero?», «ट̇y luego a dónde fueron...?».

3. Trabajar habilidades fonológicas a través de la incitación a explorar los nombres de los animales del cuento, crear nombres para otros animales con la misma regla fonológica, inventar otras reglas y jugarlas...

Vecilla, I. (2021). Atención educativa online a alumnas con discapacidad visual de 3 a 5 años: «Nuestra casa no es mi cole». RED Visual: Revista Especializada en Discapacidad Visual, 77, 200-227. https://doi.org/10.53094/ JXGW7586. 
4. Trabajar la lectura con propuestas del tipo: encontrar letras, o leer palabras, o pequeñas frases, o párrafos que previamente han escuchado, para asegurar la mínima dificultad y mayores posibilidades de éxito motivante.

5. Trabajar la escritura con propuestas significativas: buscar y escribir el nombre del animal favorito de este cuento, o de una flor que aparece en el mismo...

6. Trabajar las técnicas de trabajo intelectual (TTI), aprendiendo a utilizar los materiales para buscar información o para comprobarla: «¿Estás segura de que primero ven juncos y luego amapolas?» Incluso, crear materiales similares con ayuda.

7. Trabajar las tecnologías de la información y la comunicación (TIC): encender y apagar el ordenador, usar las teclas tabulador, espacio, enter, flechas, ampliar, pasar página, volver atrás, iniciar uso del teclado qwerty... (Organización Nacional de Ciegos Españoles, 2010).

8. Promover la alfabetización digital, en tanto que proceso con varias fases, de las cuales la primera es crucial para asegurar un aprendizaje efectivo.

9. Trabajar el currículo emocional: escucha activa, expresión facial y corporal de emociones básicas (miedo, sorpresa, alegría, tristeza, enfado...), juego simbólico, mantener diálogos y formular preguntas adecuadas a intereses y contextos, practicar la tolerancia ante la dificultad, pedir ayudas necesarias y agradecer, empatizar con sentimientos de otros, expresar emociones propias...

\subsection{La metodología}

1. Interactuar con las cuatro marionetas previamente, durante dos o más sesiones.

2. Escuchar el cuento (tres minutos).

3. Visualizar las 27 fotografías y encontrar a oso y ratón y expresar dónde están y qué se ve, y en qué posición se han puesto... (unos 30 minutos).

4. Recordar qué les va sucediendo de modo secuencial y comprobar con las fotos o con la narración oral (unos 15 minutos).

Vecilla, I. (2021). Atención educativa online a alumnas con discapacidad visual de 3 a 5 años: «Nuestra casa no es mi cole». RED Visual: Revista Especializada en Discapacidad Visual, 77, 200-227. https://doi.org/10.53094/ JXGW7586. 
5. Inventar nombres para otros animales que podrían encontrar en su paseo: Lagarto TO, Conejo JO, Mosquito QUITO, Mariquita QUITA, Oruga...

6. Leer según el nivel de cada cual: buscar letras, palabras o frases.

7. Dibujar y escribir lo que haya resultado más sugerente o motivante.

Siempre finalizar cada sesión con éxito y logros en cada propuesta que se haga. Si algo se complica, no pasa nada: será que requiere habilidades previas que hay que reforzar. Se tendrá que andar ese camino hacia la ZDR con cada alumna.

Pueden ser tres o cuatro sesiones. En el momento en el que la alumna muestre interés por recibir el material, se le puede hacer llegar, para que pueda explorarlo a su gusto (Figura 4).

Figura 4. Nueva imagen de intervención con este material

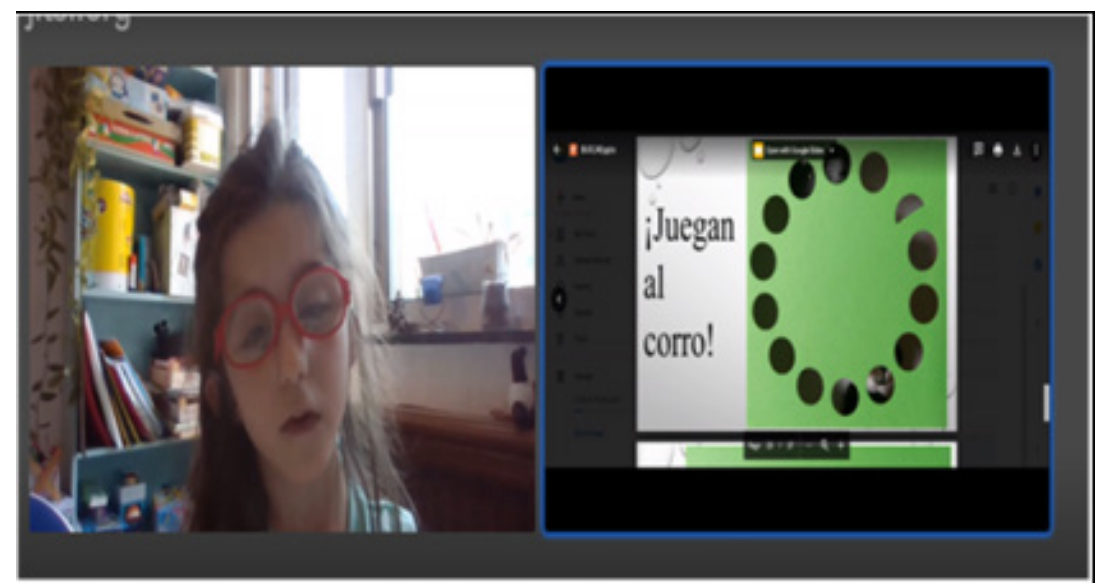

\section{El motor: las redes afectivas de nuestro cerebro}

Vamos a recordar aquí una parte de los fundamentos de la neurodidáctica respecto a cómo aprendemos los seres humanos que ya habíamos descrito al principio de este texto: las redes afectivas, aquellas especializadas en asignar significados emocionales a las tareas. Están relacionadas con la motivación y la implicación en el propio aprendizaje. En la práctica, estas redes están influidas por los intereses de las personas, el estado de ánimo o las experiencias previas. 
Es por esto que, al abordar cualquier proceso de enseñanza-aprendizaje, hemos de considerar lo emocional/motivacional como parte del currículo y de modo transversal (Escudero, 2012).

Con los materiales que presentados aquí, Nadarín y Ayúdame a buscar, se ha trabajado lo emocional, por dos motivos fundamentales: por un lado, son el motor, como ya hemos dicho, $y$, por otro lado, se corresponden con habilidades que se aprenden 0 no se aprenden, no son características personales de cada cual.

\subsection{Componentes de la inteligencia emocional}

Procede recordar ahora los componentes de la inteligencia emocional que son susceptibles de aprendizaje y que pueden pasar a formar parte del currículo -0 de la intervención educativa, como se quiera decir- de educación infantil (Ribes et al., 2005):

1. Percibir y expresar emociones:

a. Los sentimientos y emociones son, en realidad, un sistema de alarma que nos informa del entorno y del estado interno.

b. Incluye emociones evocadas por objetos, eventos..., emociones expresadas por nosotros o por los demás mediante gestos, conductas, eventos...

2. Facilitación emocional:

Generar sentimientos que faciliten el pensamiento. Emociones y pensamientos están sólidamente fusionados, de modo que el «cómo nos sentimos»:

- guía nuestra atención,

- favorece o dificulta nuestros recuerdos/memoria,

- dirige nuestro modo de razonar,

- determina motivación, esfuerzo/fatiga, resistencia, resultados ante nuevos aprendizajes... 
3. Comprensión de sentimientos y emociones.

4. Regulación emocional:

Desde la escuela y la familia se debe propiciar la práctica de las capacidades emocionales. En educación infantil, vamos a centrarnos en las fases 1-Percibir $y$ expresar emociones y 2-Facilitación emocional.

5. Cómo apoyar la percepción, la expresión y la facilitación emocional:

a. Promoviendo la exploración y la expresión verbal de emociones y del evento causante.

b. Mediante el modelado y el role-playing, para materializar la influencia de los adultos de referencia como facilitadores de aprendizaje.

c. Mediante la atención y el cuidado del clima emocional en las situaciones de enseñanza-aprendizaje, que vendrá determinado, en gran medida, por el liderazgo que ejerzan maestros, padres y madres.

d. Ampliando el vocabulario, en lenguaje verbal y no verbal, de emociones y sentimientos, de modo que se pueda traducir la excitación que pueden provocar en pensamiento comprensible por cada niño.

e. Situando el foco en las emociones placenteras que podemos obtener a través de diversidad de aprendizajes, sean motores o relacionales, estéticos, de nuevos conocimientos o adquisición de nuevas habilidades, etc.

\subsection{La presencia}

Muchos expertos nos indican que, para un buen discurrir de los procesos de ayuda, influencia o modelado en el desenvolvimiento equilibrado de los componentes de este currículo emocional que tanto va a incidir en el resto de aprendizajes, es crucial el impacto que ejerce la presencia y la figura del profesional en los procesos de aprendizaje. Fernández y Muñiz (2014) recogen en su obra distintas consideraciones hechas por otros autores, precisamente, sobre la figura del profesional:

Vecilla, I. (2021). Atención educativa online a alumnas con discapacidad visual de 3 a 5 años: «Nuestra casa no es mi cole». RED Visual: Revista Especializada en Discapacidad Visual, 77, 200-227. https://doi.org/10.53094/ JXGW7586. 
- Beautler: «La persona del profesional es ocho veces más influyente que su orientación teórica y/o el uso de unas u otras técnicas» (p. 8).

- Satir: «El instrumento más importante de la relación de ayuda, del rol de facilitador, es la persona del profesional» (p. 6).

- Minuchin y Nichols: «La responsabilidad del profesional es funcionar como persona. Esto es, conservarse básicamente humano. Esto es un triunfo» (p. 2).

\section{- Carkhuff:}

El funcionamiento del profesional como persona se define en términos de nueve variables, que son: Respeto, Empatía, Autenticidad, Especificidad, Confrontación, Impacto de personalidad, Autorrevelación, Relación al momento, Autorrealización. Y un alto nivel de funcionamiento en estas variables es lo que puede estimular el crecimiento y la mejora del aprendiz (p. 12).

Sabemos, así, qué es lo que se debe practicar y practicar como enseñantes, en relación a nuestras posibilidades de ayuda e influencia, tanto a familias como a alumnos, en tanto que figuras de referencia, facilitadores de aprendizajes y líderes en los procesos de crecimiento y ajuste emocional.

No hay que abrumarse ni desalentarse, puesto que las habilidades emocionales se aprenden, se modelan, se contagian. Solamente es preciso persistir desde la convicción de su gran potencial y su efectividad en los procesos de enseñanzaaprendizaje.

\subsection{El modelado, ¿y qué le pasó?}

En el caso de niños y niñas de la etapa de Educación Infantil, el modelado a través de narraciones y/o amigos simbólicos, es una herramienta muy efectiva. Quizá por eso, estos materiales funcionaron y dieron lugar a interesantes diálogos con las cuatro alumnas de educación infantil con discapacidad visual, respecto a sus miedos, o a cómo nos sentimos si nos dejan solos, o a cómo expresar verbalmente un enfado...

En el Cuadro 1 se puede apreciar un ejemplo de conversación-modelado, que surgió a partir del trabajo con el material Ayúdame a buscar (ver Figura 5).

Vecilla, I. (2021). Atención educativa online a alumnas con discapacidad visual de 3 a 5 años: «Nuestra casa no es mi cole». RED Visual: Revista Especializada en Discapacidad Visual, 77, 200-227. https://doi.org/10.53094/ JXGW7586. 
Alumna:

-Pero ¿Dúo pudo volver solito a casa? ¿Y no se enfadó?

Respuesta:

-iOh! Sí, iclaro que pudo volver solo a casa! Es un perrete tranquilo y muy atento. Se fija mucho en los lugares por los que pasea, y se los aprende. Y bueno, yo creo que algo enfadado estaba cuando llegó, porque él no sabía qué les había pasado a sus amigos, y nada más llegar, se puso a buscarlos por casa, porque no sabía si se habían perdido o si habían regresado sanos y salvos sin él... Así que, en cuanto les escuchó y les olió, respiró lentamente y se tumbó. Bueno, antes bebió bastante agua... Estaba nerviosete. Y al ratito, cuando ya se le había pasado aquella mezcla de susto y enfado, les dijo: «Que sepáis oso Usi, ratón Tom, vaca Ka y gallina Llina que lo he pasado fatal. He estado muy, pero que muy preocupado, porque no sabía qué os había pasado, ni dónde podíais estar. Os pido por favor, por favor, por favor - tres veces se lo repitió- que, para otros paseos, si vais a alejaros, antes me aviséis, que yo sepa que estáis bien.

Alumna:

- ¿Y qué? ¿Y ellos qué hicieron? ¿Lloraban? ¿O se reían de contentos?

Respuesta:

-Bueno... Le escucharon. Luego se miraron entre ellos y bajaron las cabecitas. Yo creo que se estaban dando cuenta de algo importante. Y luego miraron a Dúo los cuatro a la vez y le dijeron que no volverían a alejarse de él sin avisarle. Y se pusieron a jugar los cinco. ¿Qué te parece?

Figura 5. Imagen de sesión online con una alumna de 5 años

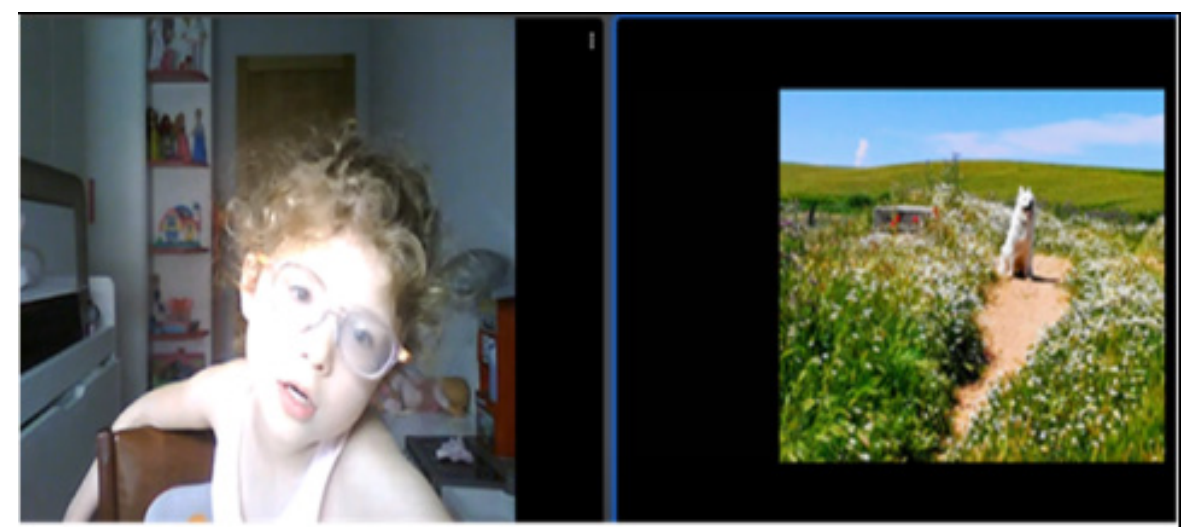

Vecilla, I. (2021). Atención educativa online a alumnas con discapacidad visual de 3 a 5 años: «Nuestra casa no es mi cole». RED Visual: Revista Especializada en Discapacidad Visual, 77, 200-227. https://doi.org/10.53094/ JXGW7586. 


\subsection{La motivación}

Una muestra del poder de la motivación en los procesos de aprendizaje puede ser este hecho, acontecido con una de las alumnas de 5 años.

Tras intervenir en un par de sesiones con el material de Ayúdame a buscar, trabajando la lectura y otras competencias curriculares, desde el interés y el juego, ella dijo que quería hacer algo así con una de sus muñecas para comprobar si íbamos a ser capaces de encontrarla.

Esta actividad tiene un alto nivel de complejidad -ya que requiere planificación, tomar decisiones, probar, comprobar, repetir, tolerar frustraciones, resolver problemas, creatividad, etc.-, razón por la cual no se había propuesto, considerando que la exigencia de habilidades y competencias para llevarla a cabo estaría por encima de la $Z D R$, incluso de la ZDP, de nuestras alumnas.

Pero si surge la intención en una alumna, entendemos que procede alentarla y pedir a los padres que adopten un rol de ayudantes de dirección y edición, explicándoles el gran valor educativo que conlleva, para una niña de 5 años con discapacidad visual, intentar hacer algo así, ya que implica practicar todas las competencias citadas: planificar, decidir, revisar, resolver, etc. Hay que ponerse a ello y lograr que, con nuestras ayudas, el éxito de la niña esté asegurado.

Así llegaron secuencias de fotografías, en las que había muñecas escondidas en la cama, entre los utensilios de la cocina, entre la ropa o entre juguetes, o en una caja de herramientas de verdad.

El poder de la motivación para poner en funcionamiento el potencial de cada aprendiz, siempre nos resulta fascinante.

\subsection{Las resistencias}

Las resistencias a los aprendizajes tienen también, en numerosas ocasiones, un origen puramente emocional.

Otra de nuestras alumnas de 5 años se negaba a leer ni una sola palabra, a pesar de que ya podía hacerlo. ¿Y por qué? 
-No sé qué sucede, pero cuando estoy yo, ella no quiere leer.

Esto decía la madre, que nos acompañaba en la sesión. La niña entonces nos comunicó que:

-Yo hago como que leo y me lo invento, que ya se lo que pasa, eso es lo que quiero hacer... Y vosotras estáis discutiendo conmigo y no me gusta.

Tras un silencio largo, añadió:

-Yo no soy la que lee, es mamá la que lee para mí.

De este modo se explicaba a su manera, expresando su miedo en términos de enfado o resistencia. A esta alumna no le hacía ninguna gracia lo que estaba sucediendo: a medida que ella mejoraba en sus habilidades lectoras, aumentaban los momentos en los que la madre le proponía que leyera, en lugar de ser ella, su madre, quien leía. Y estaba percibiendo este hecho como una amenaza más que como un logro («¿Y si ahora que ya sé leer, mamá deja de leerme cuentos?»). Este era el temor que parecía ocupar sus sentimientos actuales.

Es importante hacer llegar esta hipótesis respecto a lo que le ocurre a la madre, y el chat de estas webs de videollamadas es una buena opción para intervenir en el momento.

La madre entendió esa rebeldía e inició un diálogo muy efectivo con la pequeña, a modo de modelado:

- ¿No tendrás miedo de que yo deje de leer para ti? Porque eso no va a suceder nunca. A mí me encanta escucharte leer, pero me encanta también leer para ti. Espero que siempre me vayas a dejar hacerlo. ¿Eh? ¿Qué me dices? ¿Tú vas a leer para mí y yo para ti, siempre que queramos las dos?

Aquí está lo emocional atravesando cada proceso de nuestras vidas. Debemos escucharlo, porque es sencillamente el motor. $Y$ un motor puede pararse $y$, entonces, no sabemos qué pasa, pero el vehículo no marcha, aunque todo lo demás funcione a la perfección.

Y en el caso que nos ocupa, con alumnas de 3 a 5 años, lo emocional es difícilmente explícito. Se ha de indagar, descubrir lo que está sucediéndoles y guiarlas en su expresión adecuada, desde el respeto más absoluto. 
Alguna vez nos han planteado que, en educación infantil, al iniciarse la escolarización, la atención educativa ha de centrarse casi plenamente en lo curricular y en la interacción con iguales, y que la familia pasa ya a un segundo plano. Esta afirmación puede ser demasiado arriesgada.

De hecho, tanto desde los principios del DUA como de la educación inclusiva, se nos propone una «utilización» colaborativa y constante con la experticia de cada familia, procurando y acogiendo su implicación para la adquisición de competencias instrumentales y emocionales en cada momento.

\section{Conclusiones}

Consideramos que esta experiencia de atención y apoyo educativo online en educación infantil para cuatro alumnas con discapacidad visual a lo largo de casi cuatro meses ha permitido constatar que:

1. La atención online en educación infantil resulta especialmente compleja y con requerimientos muy específicos, algunos de los cuales hemos querido reflejar en este texto.

2. Su complejidad no debe llevarnos ni a abandonar ni a limitarnos a una intervención circunscrita a objetivos y contenidos curriculares. De hacer esto, estaríamos transfiriendo la responsabilidad de ser a la vez padres y maestros (en tanto que agentes capaces de motivar, reforzar, guiar, evaluar competencias...) a unos progenitores que, en momentos de especial vulnerabilidad y exigencia, no tienen por qué estar preparados para ello, generando frustración y desaliento innecesarios respecto al potencial de aprendizaje de sus hijos.

3. Entendemos que una de las peculiaridades de la atención educativa online en educación infantil es la configuración de una buena colaboración y sinergia con la familia en cada sesión y mientras dure todo el proceso.

4. El apoyo a las alumnas de infantil con discapacidad visual y a sus familias, cuando ha de desarrollarse en modalidad online, ha de priorizar la atención a los aspectos emocionales presentes en cada niña y en cada familia, y a su evolución. 
5. Si bien consideramos que la atención educativa online en educación infantil no resulta la modalidad más adecuada, a menos que no quede otra opción, sí hemos constatado que permite aportaciones valiosas sobre las que procede reflexionar y recoger:

a. Mejora el conocimiento y la capacidad de las familias para apoyar el aprendizaje de sus hijos, ajustándose, de modo más adecuado, a la identificación de sus dificultades y al diseño de respuestas de apoyo más acordes al potencial actual de sus hijos. Las sesiones online, en las que la familia puede estar presente y compartir el proceso - a veces observando, a veces participando-, les proporciona habilidades que en la intervención en aula no podrían adquirir.

b. Facilita una intervención individualizada y centrada en el desarrollo de competencias, desde la ZDR de cada niño, al realizar esta atención educativa fuera de los requerimientos cotidianos que impone el currículo, el ritmo del aula, etc.

c. Permite crear recursos digitales que se han mostrado muy versátiles para la atención a alumnos con discapacidad visual en esta etapa educativa.

d. Intensifica las oportunidades de práctica y aprendizaje de competencias tecnológicas.

Así pues, seguiremos buscando, en este aprendizaje a lo largo de la vida, recursos, soporte teórico, estrategias, etc. Y practicando habilidades de escucha, de manejo de herramientas digitales, etc., pues nunca sabremos con qué nuevos retos nos vamos a encontrar.

Lo que sí conocemos muy bien ahora, y podríamos decir que se impone como la conclusión más importante, es el agradecimiento a la capacidad de resiliencia (confianza, perseverancia, tolerancia a la frustración, creatividad, calidez, inspiración...) que percibimos, si nos detenemos a escuchar con tiempo y sin expectativas ni objetivos, en toda la comunidad educativa.

Es posible que algo así como una pandemia y un confinamiento inesperados no nos vuelva a suceder. También es posible que se nos presenten situaciones similares en el futuro. 
Proponemos recordar todo lo aprendido: los principios de la neurodidáctica y del DUA, de la educación inclusiva, las fundamentadas sugerencias respecto a poner en lugar prioritario un buen currículo emocional, las aportaciones de las TIC y la capacidad de resiliencia de cada agente de la comunidad educativa, conformada por diversidad de familias, aprendices y enseñantes... Todo esto, que aquí está disponible, nos brinda un mapa de fortalezas infinitas, en el cual, sin duda, merece la pena seguir buscando, pase lo que pase, en sinergia de voluntariosas vulnerabilidades, que merecen escucha, tiempo y acompañamiento.

Entendemos que, tras un trimestre de atención educativa online y dos trimestres de vuelta a las aulas en condiciones muy particulares y novedosas, ha quedado claro para toda la sociedad que el modo de afrontar estas exigencias y estos retos, por parte de la comunidad educativa, ha resultado más que exitoso.

Y este hecho ha de dejarnos a todos muy esperanzados.

\section{Referencias bibliográficas}

Alba Pastor C., Sánchez Serrano, J.M., y Zubillaga del Río, A. (2014). Diseño Universal para el Aprendizaje (DUA): pautas para su introducción en el currículo [PDF]. Educrea.

Booth, T., Ainscow, M., y Kingston, D. (2006). Index para la inclusión: desarrollo del juego, el aprendizaje y la participación en Educación Infantil [PDF]. Centre for Studies on Inclusive Education.

Escudero Muñoz, M. (2012). La educación inclusiva, una cuestión de derecho [PDF]. Educatio Siglo XXI, 30(2), 109-128.

Fernández, S., y Muñiz, B. (2014). Intervención con familias: la figura del profesional y su implicación en la atención a las familias. Grupo Zurbano de Terapia Familiar.

Lionni, L. (1963). Nadarín. Lumen.

Organización Nacional de Ciegos Españoles (2010). Competencias básicas específicas para el alumnado con discapacidad visual, atención temprana. Documento de uso interno. Organización Nacional de Ciegos Españoles. 
Ribes, R., Bisquerra, R., Agulló, M.J., Filella, G., y Soldevila, A. (2005). Una propuesta de currículum emocional en educación infantil (3-6 años) [PDF]. Cultura y Educación, $17(1), 5-17$.

Rose, D. H., y Meyer, A. (2002). Teaching every student in the digital age: Universal Design for learning. Association for Supervision and Curriculum Development.

Isabel Vecilla Rodrigo. Maestra del Equipo de Atención Educativa a Alumnos con Discapacidad Visual de Castilla y León. Dirección de Apoyo de la ONCE en Salamanca. Bermejeros, 14; 37001 Salamanca (España). Correo electrónico: ivr@once.es. 